\title{
Computer simulation of sea water pollution
}

\section{Doo Hee Han}

Department of Architectural Engineering, Chungwoon University, Incheon, 402-803, R. O. Korea

\section{Email address:}

hanknu@hanmail.net

\section{To cite this article:}

Doo Hee Han. Computer Simulation of Sea Water Pollution. International Journal of Environmental Monitoring and Analysis. Vol. 2, No. 5, 2014, pp. 266-271. doi: 10.11648/j.ijema.20140205.16

\begin{abstract}
In this paper, we proposed to use the surface water modeling system to sea water spreading simulation. We used SMS8.1 with GFGEN, RMA2 and RMA4. We assumed that there is no other effect except physical process in the sea water, and simulated the divergence of water pollution. This approach can be used in any other sea water pollution analysis. Also we showed general sequence of sea water pollution analysis by example images.
\end{abstract}

Keywords: Surface Water Modeling, Water Pollution, Water Environment, Simulation

\section{Introduction}

We started land reclamation of the Cheonsuman bay in 1980 , and completed in 1995. Two fresh water lakes were created and we named Ganwolho and Bunamho. The purposes of land reclamation were expansion of land, increase the yield of grain, guarantee of living water and the improvement of land traffic. But the water quality in the lakes became worse than before and the bottoms of lakes were rotten. In spite of this rotten problem, we made two new seawalls named Sihwaho and Saemangeum lake. Fig. 1,2,3 show so big lakes by land reclamation in Korea. So we should solve the environmental problems near land reclamation area.

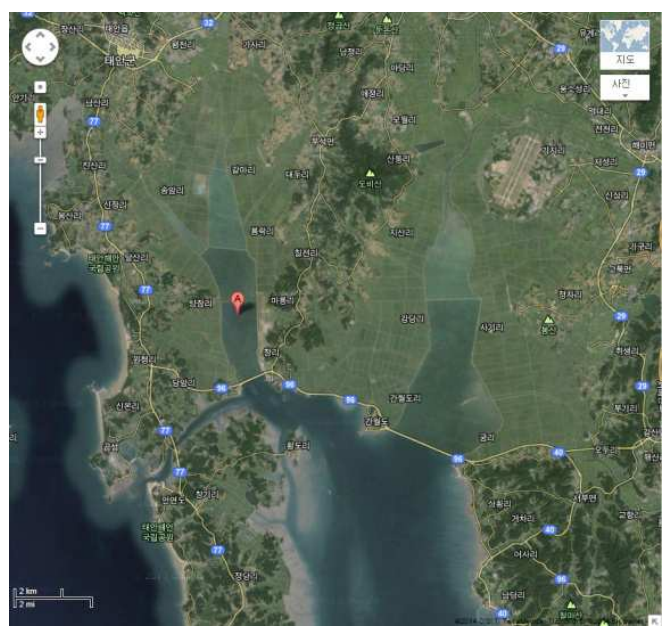

Fig 1. Ganwol and Bunam lake in Cheonsuman bay.
A long liver is connected to the coast and sea water does not have a closed running way rather than open stream. So the movement of sea water is very complicated. But if we use several conditions, sea water movement can be analyzed. So I presented sea water pollution analysis with Surface water Modeling System(SMS)[1,2,9]. The focused area was Cheonsuman bay in the west side of Korean peninsula. So in this paper I would like to introduce how to use the surface water modeling system in sea water stream.

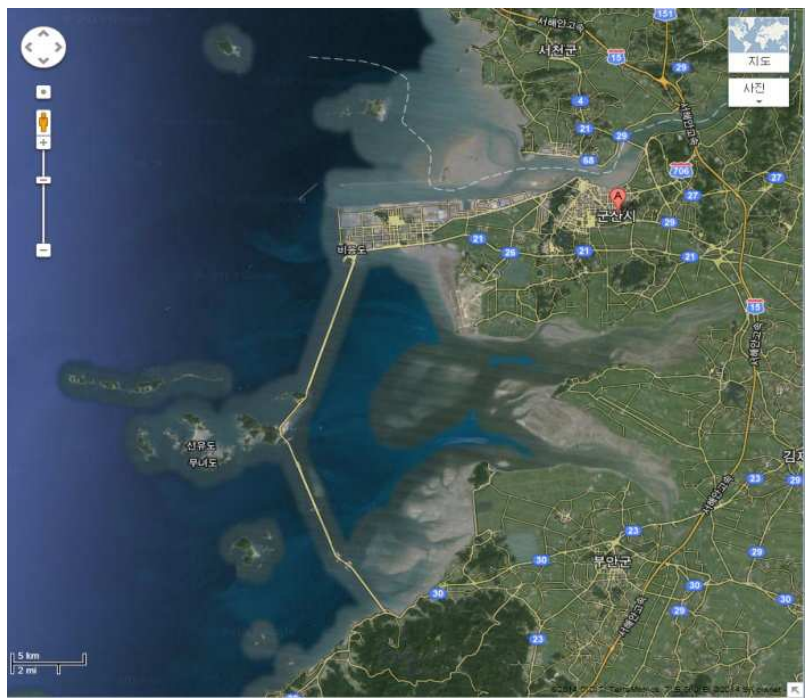

Fig 2. Saemangeum lake in Kunsan 


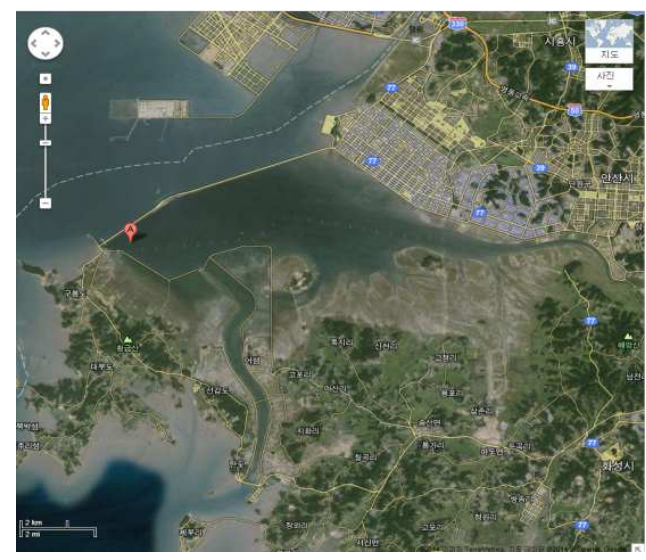

Fig 3. Sihwa lake in Incheon

\section{SMS}

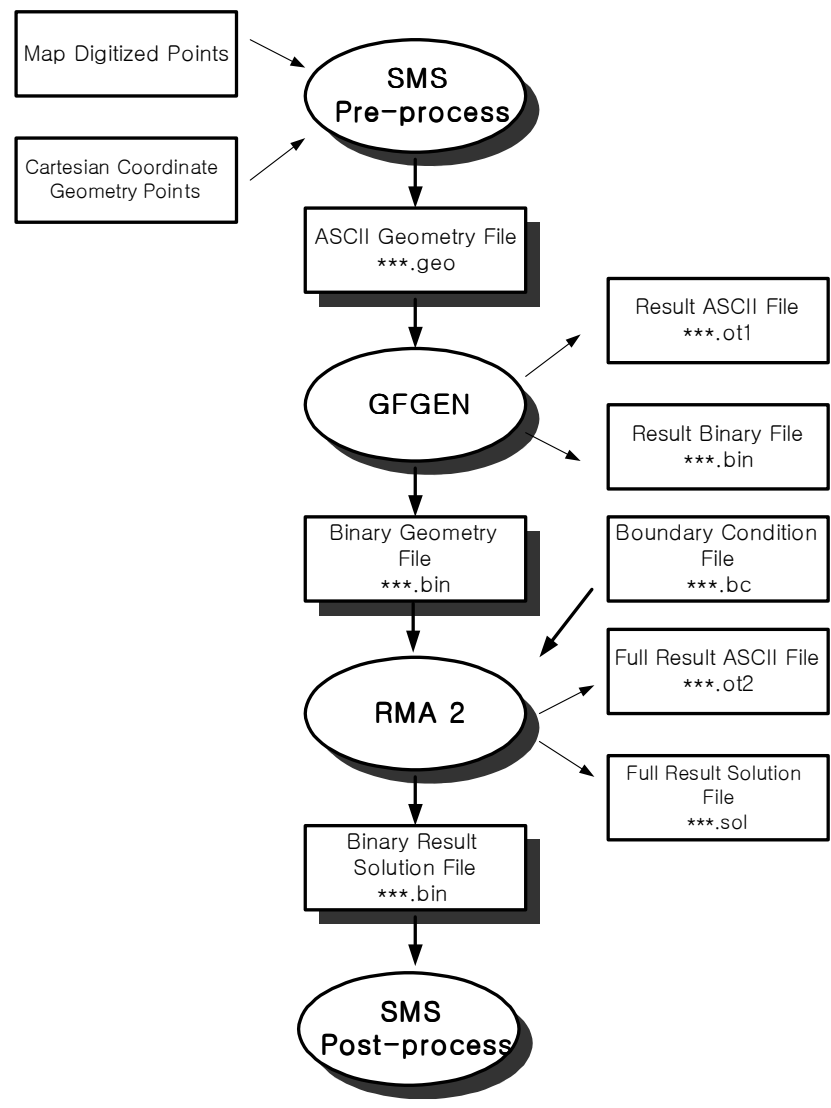

Fig 4. Flow diagram of RMA2

SMS is a pre- and post-processor for surface water modeling and analysis. It includes one-, two- and three dimensional numeric models including lumped parameters, finite element and finite difference models. Interfaces specially designed to facilitate the utilization of several numerical models comprise the models of SMS. Supported models include;

Two-dimensional riverine/estuarine circulation models RMA2, HIVEL

Three-dimensional riverine/estuarine circulation models RMA10, CH3D
Ocean circulation models ADCIRC and M2D

Phase resolving wave models CGWAVE and BOUSS2D

Non-phase resolving wave model STWAVE

Transport models RMA4 and SED2D-WES

One-dimensional riverine model HEC-RAS

The interfaces in SMS are enclosed by the USACE-Engineering Research and Development Center(ERDC) at the Waterways Experiment Station(WES) as well as the Federal Highway Administration(FHWA). Each numerical model is designed to address a specific class of problems. Some calculate hydrodydamic data such as water surface evaluation and flow velocities. Others compute wave mechanics such as wave height and direction. Still others track contaminant migration or suspended sediment concentrations. Some of the models support both steady state unsteady analyses, while others support only steady state analysis. The finite element mesh, finite difference grid or cross section entities, along with associated boundary conditions necessary for analysis, are created within SMS and then saved to model-specific files. These files are used as input to the hydrodynamic, wave mechanic, contaminant concentrations, sediment concentrations or other functional data at each node, cell or section. SMS reads this data to create plots and animations.

SMS can also be used as a pre- and post-processor for other finite element or finite difference programs as long as the program can read and write files in a supported format. To facilitate this, a generic interface is available to define parameters for a proprietary model. SMS is well suited for the construction of large, complex meshes of arbitrary shape[3].

The powerful function of SMS would be creating animations. A film loop is an animation created by SMS to display changes in data sets through time. Flow trace and particle trace animations are a special type of film loop, which use vector data sets to trace the path that particles of water will follow through the flow system.

\section{Application of SMS}

SMS provides a custom interface to the RMA2 model offering a simple way to set model parameters and a graphical user interface to run the model and visualize the results. Gather background data from a variety of sources from GIS to $\mathrm{CAD}$ and access online data from numerous databases of maps, images, and elevation data. SMS allows you to interact with models in true 3D taking advantage of optimized OpenGL graphics and to create photo-realistic renderings and animations for PowerPoint, print, and web presentations. RMA2 is a hydrodynamic modeling code that supports subcritical flow analysis, including wetting and drying and marsh porosity models. It is part of the TABS analysis package written by the U.S. Army Corps of Engineers Waterways Experiment Station (USACE-WES). The methods of analysis used by the TABS codes along with their file formats and input parameters are described in their own documents. SMS supports both pre- and post-processing for RMA2. A mesh for use with RMA2 is created and edited in 
SMS using the Mesh Module. The modeling parameters required by RMA2 are generated and applied to the mesh using commands grouped in the RMA2 menu. Post processing of solution data generated by RMA2 is done using the generic visualization tools of SMS. Fig. 5. Shows a sample of mesh(Noyo Bay).

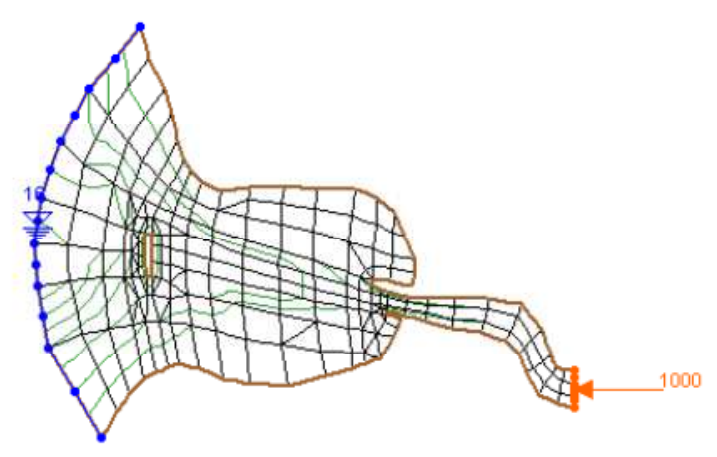

Fig 5. Noyo Mesh

This mesh was created in English units. The river flowing into Noyo Bay has a flow of 1,000 cfs. The water surface elevation on the left side varies as the tide comes in and out over a 12-hour cycle repeated twice a day.

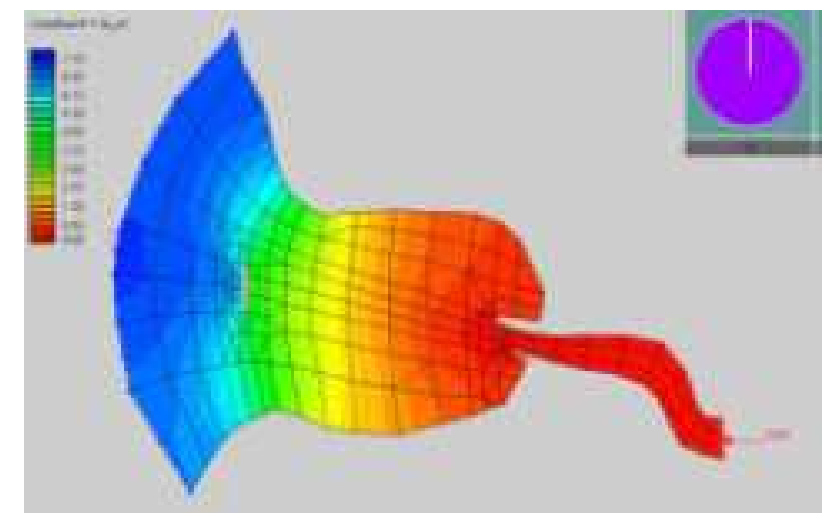

Fig 6. Animarion of stream.

Also, SMS provides a custom interface to the RMA4 model offering a simple way to set model parameters and a graphical user interface to run the model and visualize the results. Gather background data from a variety of sources from GIS to CAD and access online data from numerous databases of maps, images, and elevation data. SMS allows you to interact with models in true 3D taking advantage of optimized OpenGL graphics and to create photo-realistic renderings and animations for PowerPoint, print, and web presentations. RMA4 is part of the TABS-MD suite of programs and is used for tracking constituent flow in 2D models. RMA4 can be applied to represent the transport of a contaminant or salinity intrusion in a system. RMA4 can only be run after having initially run a hydrodynamic solution. Currently, SMS only interfaces RMA4 with a solution file from RMA2. Because RMA4 is tracking the transport or a constituent, it is by its nature a dynamic model.. RMA4 uses the flow solutions to compute the constituent concentration as it flows through the mesh. The initial hydrodynamic solution computed by RMA2 can be either steady state or dynamic. RMA4 will utilize a steady state solution repetitively, or can loop through a portion of a dynamic solution repetitively to simulate the transport over time. Fig. 6. shows example of a capture in moving picture. A clock is located in right upper side and we can change the time per each frame.

\section{The Coast Physical Understanding in the Spreading Computer Simulation}

Erase here "Whe"

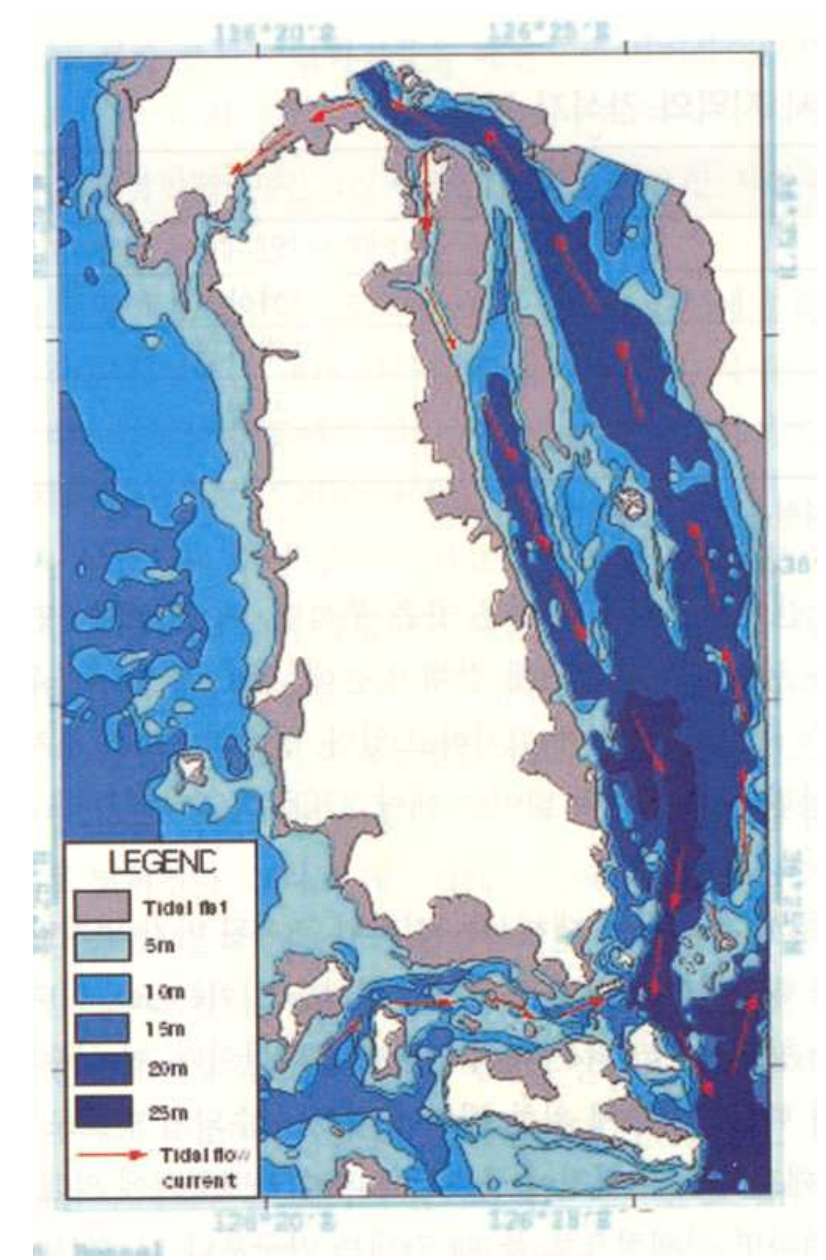

Fig 7. The map of sea depth and tide

Elements of the fluid force acting on the coast are pressure, gravity, friction, Coriolis force, the tide generating force, a force due to density difference, a force due to wind force. This can be written as equation (2.1)

$$
\frac{d \vec{v}}{d t}=\frac{1}{\rho} \nabla y+\vec{K} \nabla^{2} \vec{v}-2 \vec{\Omega} \times \vec{v}+\vec{Q}+\vec{F}
$$

Where $\rho$ is the density of sea water, $\Omega$ is a rotating angular velocity of the earth, $g$ is the gravitational acceleration, $p$ is pressure, $K$ is the diffusion coefficient of motion, $F$ forces acting on the other element of the fluid.

The ocean current is not simple and can be affected by sea 
bottom. The difference between high and low tide is caused by the gravitational interaction. The temperature of land will be higher than the sea water in a day because the specific heat of land is lower than sea water. This temperature difference makes sea wind in a day also makes land wind in the night. These winds make a drift current on the sea water by $3.5 \%$ of wind speed. The density of sea water in coastal waters is around $1,020-1,028 \mathrm{~kg} / \mathrm{m}^{3}$ and it is higher than the freshwater, so if the river water runoff the sea water, the radial density spreading phenomenon occurs because of density difference between liver water and sea water. Temperature and salinity of seawater are different but high density sea water will be generated by caballing effect on the central part of the coastal waters of the sea, the high-density vertical circulation will be increased but the effect will be minimal because of the low depth. Fig. 7 shows the map of sea depth and tide in the Cheonsuman bay.

\section{Spread Simulation}

\subsection{Shallow Water Equations and the Continuity Equation}

In shallow sea water, the density $\rho$ is assumed to be a constant number of two-dimensional fluid, and a horizontal component of velocity $(\mathrm{u}, \mathrm{v})$ is independent to the vertical direction. The waters are assumed to be incompressible fluid, the scale of the exercise is assumed very small. Phenomena governing the movement equation and the continuity equations of shallow water equations are as follows:

$$
\begin{aligned}
& \frac{\partial U}{\partial t}+\frac{\partial(u U)}{\partial x}+\frac{\partial(u V)}{\partial y}-f V=-Q H \frac{\partial \eta}{\partial x}+\frac{\alpha}{\rho}-F^{\boldsymbol{*}}+T^{\boldsymbol{v}} \\
& \frac{\partial V}{\partial t}+\frac{\partial(v U)}{\partial x}+\frac{\partial(v V)}{\partial y}+f U=-a H \frac{\partial \eta}{\partial y}+\frac{\partial}{\rho}-F^{\mathbf{n}}+T^{\mathbf{v}}
\end{aligned}
$$

The continuity equation is

$$
\frac{\partial \eta}{\partial t}+\frac{\partial U}{\partial x}+\frac{\partial V}{\partial y}=0
$$

Where $\eta$ is the displacement from standard sea level, $h$ is the depth to average submarine at sea level, $\mathrm{H}$ is water depth $\left(H=\eta+h+h_{b}\right), h_{b}$ is the displacement of the seabed, $g$ is the gravitational acceleration. $\tau_{\mathrm{x}}, \tau_{\mathrm{y}}$ the wind stress $\mathrm{x}, \mathrm{y}$ components, $\mathrm{U}, \mathrm{V}$ are integrals of $\mathrm{u}, \mathrm{v}$ from the seabed to the sea surface. $\mathrm{F}^{\mathrm{x}}, \mathrm{F}^{\mathrm{y}}$ are $\mathrm{x}, \mathrm{y}$ component of the seabed friction and, $\mathrm{T}^{\mathrm{x}}, \mathrm{T}^{\mathrm{y}}$ viscous force of the horizontal $\mathrm{x}, \mathrm{y}$-direction component.

\subsection{Simulation Plan}

We can read the sea bed data with sea map and depth map. We used a sea map of DC322 in the case of Cheonsuman bay. Also we can make mesh map by sea map. Fig. 8 is a sample of mesh map based on sea map. Fig 9 shows a sample of map around discharge gate by finite element mesh. We used SMS8.1, and applied GFGEN, RMA2 and RMA4[1,2,4,5,6,7,8,9].

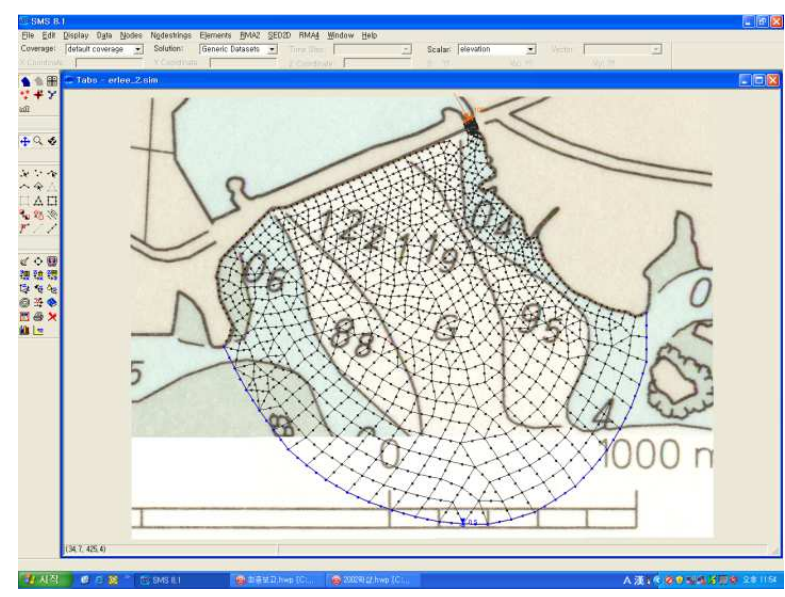

$x-y$ surface

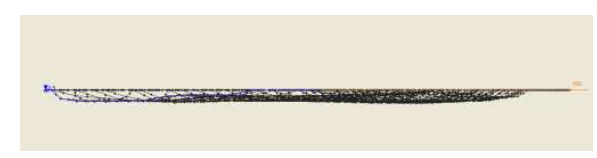

y-z surface

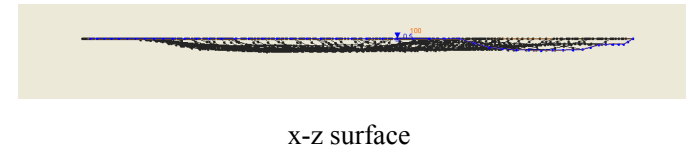

Fig 8. A sample of mesh map around discharge gate

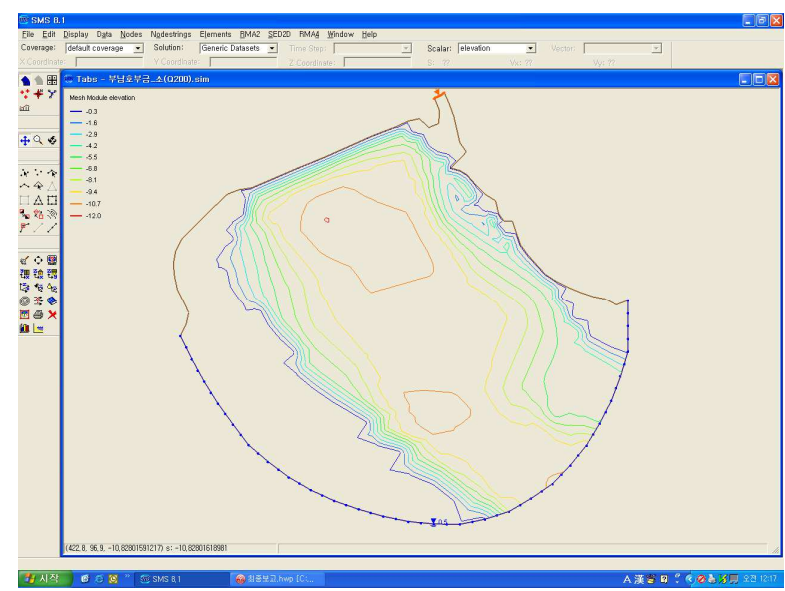

Fig 9. A sample of map around discharge gate.

\subsection{Fluid Speed Simulation}

In order to use the RMA2, we need to apply eddy viscosity and Manning value. Table 1 is list of Eddy viscosity in USACE-WES and table 2 is a list of Manning value. We can choose a suitable value of Eddy viscosity and Manning value. With these parameters SMS gives us the fluid speed field of discharged water. Fig. 10 shows an example of fluid speed field.

\section{Table 1. Eddy viscosity}

\begin{tabular}{ll}
\hline Type of Problem & $\boldsymbol{\varepsilon}$ Value[N. sec/m2] \\
\hline Homogenous horizontal flow around an island & $500-5000$ \\
Homogenous horizontal flow at a confluence & $1100-5000$ \\
$\begin{array}{l}\text { Steady-state flow for thermal discharge to a } \\
\text { slow moving river }\end{array}$ & $1000-50000$ \\
\hline
\end{tabular}


Table 2. n-value of Manning

\begin{tabular}{ll}
\hline Status & $\mathbf{n}$ value \\
\hline Shallow river & $0.025-0.035$ \\
Deep river & $0.018-0.025$ \\
Shallow river mouse & $0.020-0.030$ \\
Deep river mouse & $0.015-0.020$ \\
Wet land & $0.05-0.10$ \\
\hline
\end{tabular}

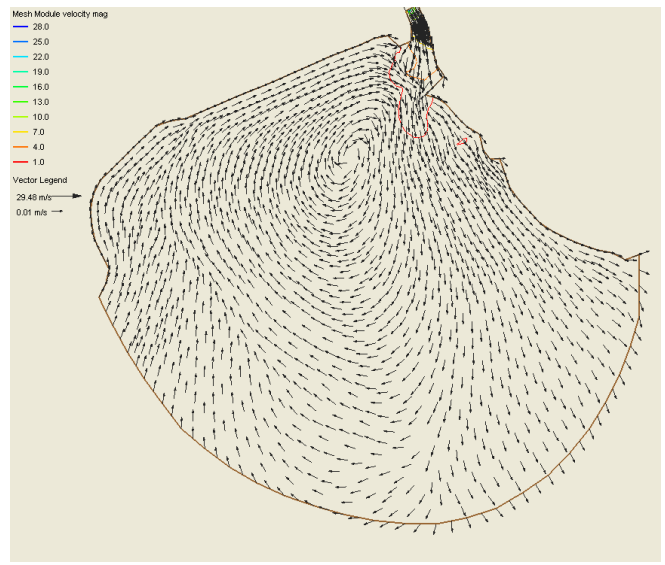

Fig 10. A sample of fluid speed field of discharged water

\subsection{Diffusion Rate Analysis}

We assume that there were only physical processes in spreading. All chemical or biological processes will be ignorable. Considerable values are COD, BOD, SS, DO, T-P and T-N, etc. Fig 11 shows an example of the COD diffusion rate of discharged water. Actually, these sequences are given by continuous moving picture, so we can easily configure the diffusion phenomena.

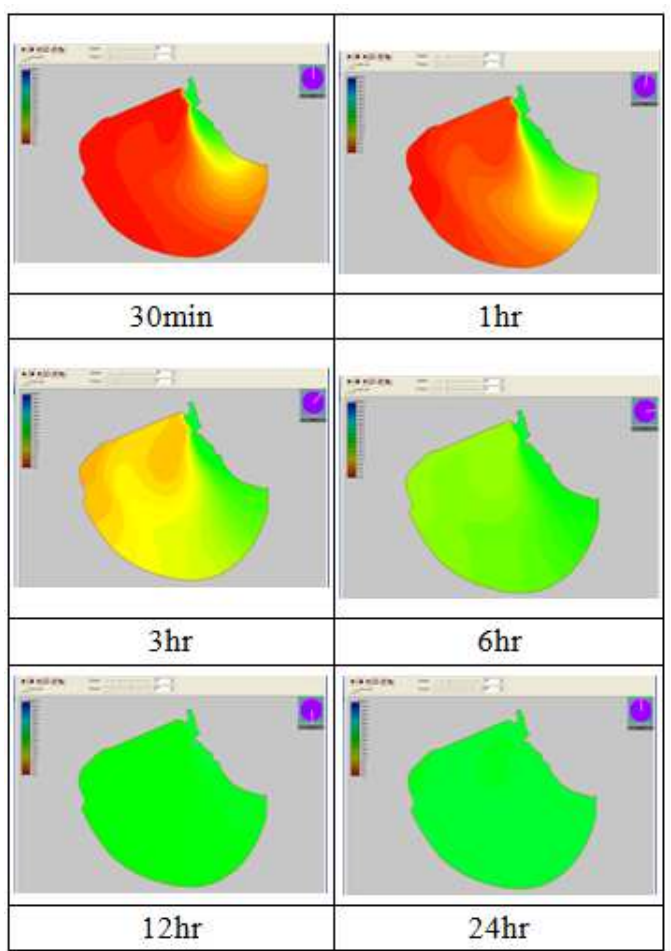

Figure 11. A sample of difusion rate of discharged water(COD).

Table 3. The standards of sea quality

\begin{tabular}{|c|c|c|c|c|c|c|}
\hline Level & pH & $\operatorname{COD}(\mathrm{mg} / \ell)$ & DO (mg/l) & MPN/ $100 \mathrm{~m} \ell$ & T-N (mg/l) & T-P (mg/l) \\
\hline I & $7.8 \sim 8.3$ & $\sim 1$ & $7.5 \sim$ & $\sim 1000$ & $\sim 0.3$ & $\sim 0.03$ \\
\hline II & $6.5 \sim 8.5$ & $\sim 2$ & $5 \sim$ & $\sim 1000$ & $\sim 0.6$ & $\sim 0.05$ \\
\hline III & $6.5 \sim 8.5$ & $\sim 3$ & $2 \sim$ & & $\sim 1.0$ & $\sim 0.09$ \\
\hline
\end{tabular}

\section{Conclusion}

We proposed to use the surface water modeling system to sea water spreading simulation. We used SMS8.1 with GFGEN, RMA2 and RMA4. We assumed that there is no flow in the sea water, and simulated the divergence of water pollution. Also we assumed that there are only physical processes in stream. This approach can be used in any sea water pollution analysis.

There are many fish farms in shallow sea near land reclamation area, so we should maintain the clean water lake which located before the bay. In my study on the Cheonsuman bay case, if they open the water gates, then fish farm area could be dangerous. Before opening the gates, we simulated the effects of polluted water by SMS, and we got a meaningful output in the sea water stream and pollution. Table 3 shows the standards of sea quality.

\section{References}

[1] D. Han Computer Simulation of Water Pollution by Opening the Water Gate of Bunam Lake in Seosan City.. Jernal of the Korea Academia-Industrial cooperation Society11 (2010). 1006-1015

[2] D. Han A Safety Study of the Fish Farm in Cheonsuman after Constructing the $\mathrm{H}$ Condominium.. Jernal of the Korea Academia-Industrial cooperation Society11(2010).4093-4099

[3] ems-i, Two- Dimensional Hydraulic Modeling of Complex Waterways with SMS, EMS-I Training Manual, ems-i,((2005).

[4] K. Han etc., Development and Application of 2-Dimensional Water Quality Model in the Down Stream of Han River, J. of Korea Water Resources Association, 35( 2002)

[5] K. Han etc., 2-Dimensional Water Dynamic Analysis by Number Model and GIS in the River, J. of the Korean Society of Civil Engineers, 21,( 2001) 
[6] Alam, M. M., et.al, Collocation finite element simulation of dam-break flows, J. of Hyd. Eng., ASCE,.121,( 1995)

[7] Hicks, F.E., et. al., Characteristic dissipative Galerkin scheme for open channel flow, J. of Hyd. Eng., ASCE, 118, (1992)
[8] Y. Lee, D. Han etc., Water Quality Improvement in Bunam Lake, Final Report to Hyundai Construction, Hanseo University,( 2005)

[9] D. Han, Waste Water Spreading Modeling by Bunam Lake Gates, Proceedings of KAIS Fall Seminar, (2009) 